Canadian

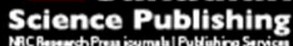

Applied Physiology, Nutrition, and Metabolism Physiologie appliquée, nutrition et métabolisme

\title{
Pre- and within meal effects of fluid dairy products on appetite, food intake, glycemia and regulatory hormones in children
}

\begin{tabular}{|r|l|}
\hline Journal: & Applied Physiology, Nutrition, and Metabolism \\
\hline Manuscript ID & apnm-2016-0251.R2 \\
\hline Manuscript Type: & Article \\
\hline Complete List of Authors: & \begin{tabular}{rl|} 
Vien, Shirley; University of Toronto, Nutritional Sciences \\
Luhovyy, Bohdan; Mount Saint Vincent Univeristy, Applied Human Nutrition \\
Patel, Barkha; Yale University School of Medicine, ; University of Toronto \\
Faculty of Medicine, Nutritional Sciences \\
Panahi, Shirin; University of Toronto, Nutritional Sciences \\
Khoury, Dalia; University of Toronto, Nutritional Sciences \\
Mollard, Rebecca; University of Manitoba Faculty of Agricultural and Food \\
Sciences, Department of Human Nutritional Sciences, Faculty of \\
Agricultural and Food Sciences \\
Hamilton, Jill; Hospital for Sick Children, Endocrinology \\
Anderson, G. Harvey; University of Toronto, Nutritional Sciences
\end{tabular} \\
\hline Keyword: & $\begin{array}{l}\text { dairy, milk, sugar-sweetened beverage, food intake, appetite hormones, } \\
\text { glycemic control, children }\end{array}$ \\
\hline \multicolumn{2}{|c}{} \\
\hline \multicolumn{2}{|c}{}
\end{tabular}


Pre- and within meal effects of fluid dairy products on appetite, food intake, glycemia and regulatory hormones in children

Shirley Vien ${ }^{1}$, Bohdan L. Luhovyy ${ }^{2}$, Barkha P. Patel $^{3}$, Shirin Panahi ${ }^{1}$, Dalia El Khoury ${ }^{1}$, Rebecca C. Mollard ${ }^{4}$, Jill K. Hamilton ${ }^{5}$, G. Harvey Anderson ${ }^{1}$

Corresponding author: G. Harvey Anderson, Ph.D., Department of Nutritional Sciences, Faculty of Medicine, University of Toronto, 150 College Street, Toronto, ON, M5S 3E2, Canada. Tel: (416) 978-1832; Fax: (416) 978-5882; E-mail: harvey.anderson@utoronto.ca

${ }^{1}$ Department of Nutritional Sciences, Faculty of Medicine, University of Toronto, Toronto, ON, M5S 3E2, Canada; ${ }^{2}$ Department of Applied Human Nutrition, Mount Saint Vincent University, Halifax, Nova Scotia, B3M 2J6, Canada; ${ }^{3}$ Department of Psychiatry, Yale University School of Medicine, New Haven, CT, 06511, USA; ${ }^{4}$ Department of Human Nutritional Sciences, Faculty of Agricultural and Food Sciences, University of Manitoba, Winnipeg, Manitoba, R3P 2N2, Canada; ${ }^{5}$ Department of Paediatrics, Hospital for Sick Children, University of Toronto, Toronto, ON, M5G 1X8, Canada.

Shirley Vien: shirley.vien@utoronto.ca; Bohdan L. Luhovyy: bohdan.luhovyy@,msvu.ca; Barkha P. Patel: bpatel@jbpierce.org; Shirin Panahi: shirin.panahi@utoronto.ca; Dalia El Khoury: khoury.dalia@gmail.com; Rebecca C. Mollard: rebecca.mollard@umanitoba.ca; Jill K. Hamilton: jill.hamilton@sickkids.ca; G. Harvey Anderson: harvey.anderson@utoronto.ca Clinical trial registry number: https://clinicaltrials.gov NCT02147496. 


\section{ABSTRACT}

The effect of beverages commonly consumed by children in-between or with meals on short-term food intake (FI) and glycemic control has received little attention. Therefore, two experiments were conducted in $9-14$ y old children following a randomized repeated measures design. Experiment $1(n=32)$ compared the effects of water (control) and isocaloric $(130 \mathrm{kcal})$ amounts of $2 \%$ milk, chocolate milk, yogurt drink and fruit punch on subjective appetite and FI. Experiment $2(n=20)$ compared the effects of isocaloric $(130 \mathrm{kcal})$ amounts of $2 \%$ milk and fruit punch on subjective appetite, FI, glycemic and appetite hormone responses. One serving of the beverages was given as a pre-meal drink at baseline $(0 \mathrm{~min})$ and a second serving $60 \mathrm{~min}$ later with an $\mathrm{ad}$ libitum pizza meal. Meal FI in Experiment 1 was lower by $14 \%$ and 10\%, respectively after chocolate milk and yogurt drink $(p<0.001)$, but not milk, compared to water. Cumulative energy intake (beverages plus meal) was higher after caloric beverages than water. In Experiment 2, no differences occurred in pre-meal but post-meal glucose was $83 \%$ higher in overweight/obese than normal weight children $(p=0.02)$. Milk led to higher pre-meal glucagon-like peptide-1 and postmeal peptide YY than fruit punch $(p<0.01)$ but insulin did not differ between treatments. In conclusion, dairy products consumed before and with a meal have more favourable effects on FI, appetite and satiety hormones than a sugar-sweetened beverage, but all caloric beverages result in more cumulative calories than if water is the beverage.

Keywords: dairy, milk, sugar-sweetened beverage, food intake, appetite hormones, glycemic control, children 


\section{INTRODUCTION}

The prevalence of obesity amongst children and youth has more than doubled within the last 25 years (Janssen 2013; Shields and Tremblay 2010). While the causes of obesity are complex and multi-factorial, one causative factor for this rise includes the changing food supply, which contributes to reduced consumption of traditional foods and increased intake of inexpensive and energy dense foods and beverages. Associated with the increase in childhood obesity has been the increase in sugar-sweetened beverages (SSB) and decrease in milk consumption (Dietz 2006; Garriguet 2008; Huang and McCrory 2005).

Milk is a good source of high quality nutrients, yet Canadian children and youth $(9-18$ y old) consume less than the Canada's Food Guide recommended $3-4$ servings of dairy per day (Garriguet 2008). Observational studies in children and adolescents indicate associations between increased dairy and calcium supplementation and lower body fat independent of total energy intake (Huang and McCrory 2005; Novotny et al. 2004; Skinner et al. 2003). However, only one randomized trial has been reported and gives partial support for these associations. Supplementation of milk to $8-10$ y old overweight $(\mathrm{OW})$ children for 16 wk resulted in no changes in fat loss or body weight but glucose tolerance tests revealed that OW children with high milk consumption ( 4 servings of milk/d) reduced insulin area under the curve compared to low milk consumption (1 serving of milk/d) (St-Onge et al. 2009), suggesting it reduced insulin resistance.

In adults, in contrast to children, the role of dairy consumption on control of energy intake and body weight is well documented. Epidemiological studies show an inverse association between higher dairy consumption and reduced body weight (Dougkas et al. 2011; Loos et al. 2004), incidence of obesity (Dougkas et al. 2011; Marques-Vidal et al. 2006) and components of the metabolic syndrome (Pereira et al. 2002). Short-term experimental trials show that milk 
consumption reduces appetite and food intake (FI) compared to a fruit drink (Dove et al. 2009) and when consumed prior to (Panahi et al. 2013a) or within (Panahi et al. 2013b) meals reduces post-meal glycemic response compared with other commonly consumed beverages. These effects of milk have been attributed to its components, including milk proteins (whey protein and casein) (Akhavan et al. 2014), carbohydrate (lactose) and fat (Panahi et al. 2014).

To date, no experimental studies have reported the short-term effects of fluid dairy products on subjective appetite, FI, and glycemic and appetite hormone responses in children. Therefore, the objective of this study was to examine the effects of isocaloric $(130 \mathrm{kcal})$ amounts of $2 \%$ milk, $1 \%$ chocolate milk, $1.5 \%$ yogurt drink, fruit punch (SSB) and water (control) consumed before and within a pizza meal 60 min later on satiety and FI in normal weight (NW) and $\mathrm{OW} / \mathrm{obese}(\mathrm{OB})$ children (Experiment 1 ), and to compare the effects of $2 \%$ milk and fruit punch consumed before and within a pizza meal 60 min later on FI, blood glucose, and appetite hormone responses in NW and OW/OB children (Experiment 2). We hypothesized that fluid dairy products consumed before and with a meal decrease FI, increase satiety and improve postprandial hyperglycemia and appetite hormone responses in children when compared with a SSB. 


\section{PARTICIPANTS AND METHODS}

\section{Study Design}

Two experiments were conducted using a randomized, controlled, within-subject and repeated measures design. Children received beverage treatments one week apart in a randomized order using a randomized block design, which was generated with a random generator script in SAS version 9.2. Experiment $1(n=32: 16 \mathrm{NW}, 16 \mathrm{OW} / \mathrm{OB})$ completed the study with treatments of $2 \%$ milk, $1 \%$ chocolate milk, $1.5 \%$ yogurt drink, fruit punch and water (control) and in Experiment $2(n=20: 10 \mathrm{NW}, 10 \mathrm{OW} / \mathrm{OB})$ the treatments were $2 \%$ milk and fruit punch. One serving $(130 \mathrm{kcal})$ of the beverages was provided $2 \mathrm{~h}$ after breakfast $(0 \mathrm{~min})$ and a second serving 60 min later with an ad libitum pizza meal. Satiety, blood glucose and appetite hormones were measured at baseline and intervals before and after the meal, and mealtime pizza intake was measured.

\section{Participants}

Children between the ages of $9-14$ y old and with a BMI percentile ranging from the $5^{\text {th }}$ and $85^{\text {th }}$ for NW, $85^{\text {th }}$ and $97^{\text {th }}$ for OW, and greater than $97^{\text {th }}$ for OB age- and sex-specific BMI percentiles (de Onis et al. 2007) were recruited through newspaper advertisements, the Research4kids database at the Hospital for Sick Children and by word of mouth. No children participated in both studies. Children were excluded from the study if they were taking medications, regularly skipped breakfast, were lactose intolerant, had other food sensitivities or allergies and were unable to follow instructions. Eligible children were invited with their parents for a screening at the Department of Nutritional Sciences, University of Toronto, and informed written consent was obtained from parents and written assent from the child. Height (m) and body weight $(\mathrm{kg})$ were measured to determine the age- and sex-specific BMI percentile using the WHO BMI-for-age growth reference chart (de Onis et al. 2007). Bioelectrical impedance analysis 
was used to estimate body fat mass and fat free mass (RJL Systems BIA, 101Q) based on the Horlick equation (Horlick et al. 2002). Restrained eating was assessed in all children using the Dutch Eating Behaviour Questionnaire (van Strien et al. 1986). The procedures of the study were approved by the Human Subject Review Committee, Ethics Review Office at the University of Toronto and the Research Ethics Board, Hospital for Sick Children.

\section{Beverages}

Beverages (Table 1) included (1) 2\% milk (2\% M.F.; Beatrice ${ }^{\circledR}$, Parmalat, Toronto, ON) because it is the most commonly consumed type of milk amongst Canadians and children; (2) chocolate milk (1\% M.F.; Beatrice ${ }^{\circledR}$, Parmalat, Toronto, ON) because it is the most commonly consumed flavoured milk; (3) strawberry flavoured yogurt drink (1.5\% M.F.; Yoplait ${ }^{\circledR}$, Aliments Ultima Inc., Longueil, QB) because it is the second most consumed fluid dairy product (Canadian-Dairy-Information-Centre 2013); (4) fruit punch (Tropical Rhythms ${ }^{\circledR}$, Grace Foods, Richmond Hill, ON), the SSB and (5) water (control). All beverages except water were isocaloric $(130 \mathrm{kcal})$ and served chilled in an opaque cup. To match for volume of milk $(250 \mathrm{~mL})$ and to minimize aftertaste of the beverages, water was provided following chocolate milk $(191 \mathrm{~mL}+59$ $\mathrm{mL}$ of water), yogurt drink (173 mL $+77 \mathrm{~mL}$ of water), and fruit punch $(232 \mathrm{~mL}+18 \mathrm{~mL}$ of water). The rationale for providing the beverage twice was that the $1 \mathrm{~h}$ interval between the beverage and the meal reflects a pattern where children consume a beverage, such as after school while waiting for the main meal. In addition, we have previously reported that consumption of drinks containing $50 \mathrm{~g}$ of whey protein or glucose with an interval of $60 \mathrm{~min}$ or less between preload intake and a meal has a significant effect on FI at the meal (Bellissimo et al. 2008).

\section{Experimental Procedures}

Procedures are similar to those reported previously (Akhavan et al. 2014; Bellissimo et al. 2008; Panahi et al. 2014; Panahi et al. 2013b; Panahi et al. 2013a; Patel et al. 2011). In 
Experiment 1, sessions took place on five separate mornings at the Department of Nutritional Sciences, University of Toronto and in Experiment 2 sessions took place on two separate mornings at the Physiological Research Unit, The Hospital for Sick Children. Each session was 1 wk apart, children were given a standardized breakfast to consume at home so that they would arrive neither hungry nor full. The breakfast $(300 \mathrm{kcal})$ consisted of Beatrice ${ }^{\circledR}$ fat-free skim milk (250 mL, 90 kcal), Honey Nut Cheerios ${ }^{\circledR}(26 \mathrm{~g}, 100 \mathrm{kcal}$; donated by General Mills, Inc.) and Tropicana Orange Juice ${ }^{\circledR}(236 \mathrm{~mL}, 110 \mathrm{kcal})$. Participants consumed the standardized breakfast following a $12 \mathrm{~h}$ overnight fast at their preferred time in the morning (07:00 - 09:00) at the same time each week, and were asked not to consume anything except for water which was permitted up to $1 \mathrm{~h}$ before the session. Sessions began $2 \mathrm{~h}$ following the breakfast (09:00 - 11:00).

Upon arrival, trained research assistants interviewed children to ensure their compliance to instructions. Children completed 'Motivation to Eat' and 'Physical Comfort' Visual Analogue Scale (VAS) questionnaires, which have been used in previous studies (Bellissimo et al. 2008; Patel et al. 2011), at baseline and during regular intervals (15 - $30 \mathrm{~min})$ over $145 \mathrm{~min}$. Children were instructed to read each question carefully before marking an " $\mathrm{X}$ " anywhere along the 100 $\mathrm{mm}$ line anchored by opposing statements at opposite ends of the line that best reflected their feelings at that time. The Motivation to Eat questionnaire assessed desire to eat, hunger, fullness, and prospective food consumption and was used to calculate average subjective appetite scores (Stubbs et al. 2000). Average appetite score was calculated at each time of measurement for each beverage using the following formula: Average Appetite score $(\mathrm{mm})=[$ desire-to-eat + hunger + $(100$ - fullness $)+$ prospective consumption] / 4, which reflects the 4 questions of the Motivation to Eat VAS (Anderson et al. 2002).

Children received the first serving of the beverage at baseline $(0 \mathrm{~min})$ and were allowed 5 min to drink. The children engaged in a quiet activity such as reading or card and board games 
(Bellissimo et al. 2008; Patel et al. 2011) until they were escorted to the feeding room, seated in individual cubicles at 60 min and given the second serving of the beverage with an ad libitum pizza meal. Children were asked to remain seated for the duration of the meal, and were instructed to "eat until you are comfortably full" and "drink all of the drink" over the duration of $25 \mathrm{~min}$. Children consumed the entire beverage and ate the pizza in any order they preferred.

Pizzas were baked at $220^{\circ} \mathrm{C}$ for $8 \mathrm{~min}$ and served fresh every $8 \mathrm{~min}$. Two varieties, pepperoni and three-cheese, of Deep 'N Delicious 5” diameter pizzas (McCain Foods Ltd, Florenceville, NB, Canada) were served. Each tray contained 3 pizzas ( $\sim 540 \mathrm{kcal})$ : two of their first choice and one of their second choice. Cooked pizzas were cut into four equal pieces, arranged in a non-uniform fashion and weighed ( $\mathrm{g}$ ) before serving; the amount left after the meal was subtracted from the initial weight. Each variety of pizza was weighed separately, and energy consumed (kcal) at the meal was calculated using manufacturer information. Sweetness and pleasantness of the beverages and palatability of the meal using VAS questionnaires were completed immediately after beverage consumption at $5 \mathrm{~min}$ and post-meal at $85 \mathrm{~min}$.

\section{Experiment 2}

In Experiment 2, 2\% milk and fruit punch were used because of the greater protein $(8 \mathrm{~g} /$ $250 \mathrm{~mL})$ and carbohydrate $(32 \mathrm{~g} / 232 \mathrm{~mL})$ content in each beverage, respectively. As such, milk is expected to provide better glucose control than fruit punch as demonstrated in other beverage studies (Panahi et al. 2013b; Panahi et al. 2013a). The same procedure as Experiment 1 was followed except for the insertion of an indwelling intravenous catheter in the antecubital vein by a registered nurse following the completion of baseline questionnaires. Two baseline blood samples were collected followed by samples collected at $30,60,85,115$, and 145 min after the consumption of the pre-meal beverage. Children were asked to remain seated for the duration of the experimental session, and were permitted to engage in a quiet activity. 
Whole blood was collected in 3.5 mL BD Vacutainer® SST Plus serum tubes (BD Diagnostics, Franklin Lakes, NJ, USA) coated with silicone and micronized silica particles to accelerate clotting for serum sample collection, and in $2.0 \mathrm{~mL} \mathrm{BD}{ }^{\mathrm{TM}} \mathrm{P} 800$ tubes (BD Diagnostics, Franklin Lakes, NJ, USA) containing spray-dried $\mathrm{K}_{2}$ EDTA anticoagulant, DPP-IV and proprietary additives to prevent the immediate proteolytic breakdown of hormones in plasma samples. The tubes were centrifuged (Allegra X-22R, Beckman Coulter) at 1300 RCF for 10 min at $4{ }^{\circ} \mathrm{C}$. Collected serum and plasma were aliquoted into Eppendorf tubes and stored at $-70^{\circ} \mathrm{C}$ for analyses, as previously described (Patel et al. 2014). Plasma ghrelin samples were immediately treated with $1 \mathrm{~N} \mathrm{HCl}$ and phenylmethanesulfonyl fluoride $(10 \mathrm{mg} / \mathrm{mL}$ methanol $)$ per $\mathrm{mL}$ of plasma to prevent protein cleavage. Serum concentrations of glucose and insulin, and plasma concentrations of the anorexigenic gut hormones glucagon-like peptide-1 (GLP-1) and total peptide tyrosine tyrosine (PYY) and of the appetite-stimulating gut hormone total ghrelin were measured. Serum concentrations of glucose and insulin were measured at 0 (baseline), 30, 60, 85, 115 and 145 min. Plasma concentrations of GLP-1, PYY and ghrelin were measured at 0, 60, and 115 min post beverage consumption.

Serum glucose was measured using the enzymatic hexokinase method (intra-CV: $<5 \%$; inter-CV: $<8 \%$; Roche Diagnostics, Indianapolis, IN, USA). Insulin was assessed with an electrochemiluminescence assay "ECLIA" (intra-CV: $<3 \%$; inter-CV: $<7 \%$; Roche Diagnostics, Indianapolis, IN, USA). These analyses were carried out by the Pathology and Laboratory Medicine Department at Mount Sinai Hospital (Toronto, ON, Canada). Active GLP-1 (intra-CV: $<8 \%$; inter-CV: $<5 \%$; \#EGLP-35K), total PYY (intra-CV: $<6 \%$; inter-CV: $<8 \%$;

\#EZHPYYT66K), and total ghrelin (intra-CV: $<2 \%$; inter-CV: $<8 \%$; \#EZGRT-89K) were analysed with commercially available ELISA kits (Millipore, Billerica, MA, USA).

\section{Statistical Analyses}


Statistical analyses were carried out using SAS version 9.2 (SAS Institute Inc., Carey NC, USA). Two-tailed unpaired t-test were used to determine differences between body weight groups for baseline participant characteristics in each experiment and hormone measures in Experiment 2. Sex was initially included as a factor affecting FI, glucose and appetite hormones; however, it was removed when there was no effect. Two-way repeated measures analysis of variance (ANOVA) using SAS PROC MIXED procedure were performed to investigate the effect of beverage (Experiment 1: control vs. milk vs. chocolate milk vs. yogurt drink vs. fruit punch; Experiment 2: milk vs. fruit punch), and body weight group (NW vs. OW/OB) and their interaction on all dependent measures including FI (pizza kcal), energy intake at the meal (pizza $\mathrm{kcal}+$ beverage at the test meal kcal), cumulative energy intake (pre-meal beverage kcal + pizza $\mathrm{kcal}+$ beverage at the test meal kcal), caloric compensation, post-meal sweetness and pleasantness of the beverage and pizza meal. Food intake in kcal was expressed in total and corrected for body weight $(/ \mathrm{kg})$ because of the large weight differences in the two groups of children.

Caloric compensation was calculated using the following equation: Caloric compensation $(\%)=[(\mathrm{kcal}$ consumed at meal after water control $-\mathrm{kcal}$ consumed at meal after preload $) / \mathrm{kcal}$ in the preload] x 100 . A caloric compensation shown by greater than $100 \%$ reduction indicated overcompensation and less than $100 \%$ indicated low compensation for the beverage energy at the pizza meal.

Average subjective appetite scores, serum concentrations of glucose and insulin and plasma concentrations of appetite hormones were calculated as mean changes from baseline and were grouped into pre- $(0-60 \mathrm{~min})$ and post-meal $(60-145 \mathrm{~min})$ periods. Pre-meal changes from baseline were calculated as the difference from $0 \mathrm{~min}$ (immediately before beverage consumption) and post-meal changes were calculated as the difference from $60 \mathrm{~min}$ (before test 
meal consumption). Three-factor ANOVA analyses were performed to determine the effects of time, beverage, body weight and their interactions on change from baseline average appetite, serum concentrations of glucose and insulin and plasma concentrations of appetite hormones. When an interaction was found, a one-way ANOVA was performed followed by Tukey-Kramer post-hoc test to compare the effect of beverages and body weight groups on serum glucose and insulin, and plasma hormonal responses at each time of measurement.

All results are presented as mean \pm standard error of the mean (SEM). Statistical significance was considered at $p$-value of less than 0.05 . 


\section{RESULTS}

\section{Participant Characteristics}

In Experiment 1, 36 children were recruited into the study, but four children were excluded due to their noncompliance or failure to consume all five treatments, therefore data was analyzed for 32 participants ( $n=32$, Table 2$)$; sixteen NW ( 8 females, 8 males), eight OW (4 females, 4 males) and eight OB (4 females, 4 males). In Experiment 2 ( $n=20$, Table 2), 20 children were recruited and ten NW ( 5 females, 5 males), three OW (1 female, 2 males) and seven OB (4 females, 3 males) children completed the two experimental sessions.

Overweight/obese children reported higher restraint scores than NW children $(p=0.006$, Table 2) in Experiment 2, but there were no differences in Experiment 1. In both experiments, fat-free mass was not statistically different in $\mathrm{OW} / \mathrm{OB}$ and NW children but the higher body weight of the OW/OB group was explained by their 3 -fold higher fat mass $(p<0.01)$. Pooled for treatments, baseline concentrations of serum glucose and insulin, and plasma GLP-1and ghrelin were similar between body weight groups, but PYY was lower in OW/OB than NW children (Table 2).

\section{Experiment 1}

\section{Food Intake and Caloric Compensation}

Energy (kcal) intake from pizza, energy intake at the meal (pizza + beverage) and cumulative energy intake (pre-meal beverage + pizza + beverage at the test meal) were affected by beverage treatment ( $p<0.05$, Table 3), but not by body weight group or their interaction.

Pre-meal and within meal consumption of chocolate milk and yogurt drink reduced mean pizza intake by $14 \%(p<0.001)$ and $10 \%(p=0.01)$, respectively, compared to water but not to milk or fruit punch. Energy intake from beverage and pizza at the meal was higher only if it contained fruit punch $(12 \%, p=0.03)$ compared to water. Cumulative energy intake was higher after all caloric beverages compared to water $(p<0.001)$. 
When FI was corrected for body weight, there was an effect of beverage $(p<0.02$, Table 3 ) and body weight group ( $p<0.004)$, but again no beverage by body weight interaction was found. Although beverage effects were not affected by body weight, NW children consumed more pizza calories per $\mathrm{kg}$ body weight $(18.2 \mathrm{kcal} / \mathrm{kg})$ than $\mathrm{OW} / \mathrm{OB}$ children $(13.4 \mathrm{kcal} / \mathrm{kg}, p=$ 0.005, Table 3). Compensation in food consumed for the energy in the beverages was low for all dairy beverages, averaging $65 \%$. However, chocolate milk had greater caloric compensation compared to fruit punch ( $91 \%$ vs. $29 \%, p<0.01$, Table 3$)$.

\section{Subjective Appetite}

Pre-meal $(0-60 \mathrm{~min})$ average appetite scores were affected by time $(p<0.001)$, with appetite increasing over the pre-meal period. Average appetite was also affected by beverage ( $p=$ $0.004)$ and a beverage by body weight group interaction $(p=0.009)$. Pre-meal average appetite scores increased more after milk compared to fruit punch $(34 \%, p=0.03)$, chocolate milk $(44 \%$, $p=0.04)$, and water $(60 \%, p=0.006)$, with no differences compared to the yogurt drink (Figure 1A). The interaction effect can be explained by a beverage effect in NW children $(p<0.001$, Figure 1B) but not in $\mathrm{OW} / \mathrm{OB}$ children (Figure 1C).

Post-meal $(60-145 \mathrm{~min})$ average appetite scores were affected by time $(p<0.001)$, beverage $(p=0.001)$ and an interaction between beverage and body weight group $(p<0.001)$. Compared to the yogurt drink, milk and fruit punch induced greater reductions from baseline averaging 14\% $(p<0.001)$ and $8 \%(p=0.04)$, respectively (Figure 1A). However, none of the caloric beverages reduced appetite more than water. The interaction occurred because average appetite was affected by beverage type in NW but not OW/OB children. In NW children, postmeal average appetite scores were reduced more by milk than by chocolate milk or yogurt $(p<$ 0.02 , Figure 1B).

\section{Experiment 2}




\section{Food Intake}

Pizza intake, energy intake at the meal and cumulative energy intakes were affected by body weight group ( $p=0.04$ ), but not by beverage or their interaction. Overweight/obese compared to NW children, consumed 30\% more pizza calories (Table 3). When FI was adjusted per kg body weight there was no effect of beverage, body weight or their interaction.

\section{Subjective Appetite}

Pre-meal average appetite was affected by time $(p=0.03)$, beverage $(p=0.02)$ and a beverage by body weight interaction $(p<0.05)$ but not by body weight group, beverage by time or a body weight by time interaction. Pre-meal average appetite increased more after milk compared to fruit punch (Figure 2A) but only in OW/OB ( $p=0.01$, Figure $2 \mathbf{C})$. In the post-meal period, average appetite scores reduced over time $(p=0.01)$, and were affected by beverage $(p=$ 0.03), but not by body weight group or beverage by body weight interaction. Irrespective of body weight, milk reduced post-meal average appetite by $8 \%$ compared to fruit punch.

\section{Serum Glucose Concentrations}

Change from baseline blood glucose concentrations $(\mathrm{mmol} / \mathrm{L})$ were affected by time $(p<$ 0.001 ) with values peaking at $30 \mathrm{~min}$ after the pre-meal beverage and again at $85 \mathrm{~min}$, immediately after the meal (Supplementary figure S1). During the pre-meal $(0-60 \mathrm{~min})$ period, no differences due to beverages, body weight group or their interaction were observed (Table 4). Pre-meal glucose was higher in NW children but not statistically significantly different from $\mathrm{OW} / \mathrm{OB}(\mathrm{NW} 0.40 \pm 0.13 \mathrm{mmol} / \mathrm{L}, \mathrm{OW} / \mathrm{OB} 0.28 \pm 0.13 \mathrm{mmol} / \mathrm{L}, p>0.05)$

Post-meal $(60-145 \mathrm{~min})$ glucose concentrations were affected by body weight $(p<0.04)$ with higher post-meal glucose in OW/OB than NW children (Figure 3), but no effect of beverage or interaction. Post-meal glucose was $83 \%$ higher in OW/OB than NW children. Between pre and 
post-meal, there was a $33 \%$ decrease in glucose for NW and a $132 \%$ increase in glucose for OW/OB children.

\section{Serum Insulin Concentrations}

Insulin concentrations $(\mathrm{pmol} / \mathrm{L})$ changes from baseline were affected by time $(p<0.001)$ but not body weight group or beverage, with values peaking at $30 \mathrm{~min}$ after the pre-meal beverage and to a greater degree at $85 \mathrm{~min}$ immediately after the meal (Supplementary figure S1). Pre- $(0-60 \mathrm{~min})$ and post-meal $(60-145 \mathrm{~min})$ insulin were not affected by beverage, body weight group or their interactions.

\section{Plasma GLP-1 Concentrations}

Change from baseline GLP-1 concentrations were affected by time $(p<0.001)$ with values peaking at $115 \mathrm{~min}, 30 \mathrm{~min}$ after the meal (Supplementary figure S2). There was also a trend for sex $(p=0.058)$ with greater GLP-1 in female than male participants. During the premeal ( $0-60$ min) period, GLP-1 was affected by pre-meal beverage $(p<0.05$, Figure 4A) with milk resulting in higher GLP-1 response. Post-meal (60 - $115 \mathrm{~min})$ GLP-1 was not affected by beverage, body weight group or their interaction.

\section{Plasma Total PYY Concentrations}

Change from baseline PYY concentrations was affected by time $(p<0.001)$ with values peaking at $115 \mathrm{~min}, 30 \mathrm{~min}$ after the meal (Supplementary figure S2). Pre-meal (0 - $60 \mathrm{~min})$ PYY was not affected by beverage, body weight group or an interaction. Post-meal (60 - 115 min) PYY concentrations were affected by beverage ( $p<0.04$, Figure 4B), but not body weight or a beverage by a body weight interaction. Post-meal PYY response was greater after milk than after fruit punch $(p<0.04)$.

\section{Plasma Total Ghrelin Concentrations}


Ghrelin concentrations expressed as changes from baseline were affected by time $(p<$ $0.01)$ with values decreasing below baseline (Supplementary figure S2). Pre- $(0-60 \mathrm{~min})$ and post-meal (60 - $115 \mathrm{~min})$ ghrelin changes from baseline were not affected by body weight group, beverage (Figure 4C) and beverage by body weight interaction. 


\section{DISCUSSION}

The results of this study provide support for the hypothesis that isocaloric dairy products consumed before and with a meal reduce FI and appetite more than fruit punch, a SSB. The study also provides preliminary data showing that a serving of milk, compared with a SSB, results in more favourable responses in satiety hormones in both NW and OW/OB children. Post-meal metabolic responses were driven primarily by the large amount of food consumed at mealtime, but exaggerated in OW/OB children.

The effect of two servings of isocaloric dairy products on appetite and FI was not consistent. Yogurt and chocolate milk, but not milk, consumed before and with the meal reduced pizza intake compared to water, whereas the SSB at mealtime increased it (Table 3). Although milk protein is understood to be the primary component of milk and milk products that affects both FI and metabolic regulation (Akhavan et al. 2014; Panahi et al. 2014), the present data contrast that assumption. Milk with the highest protein content $(8 \mathrm{~g} / 250 \mathrm{~mL})$ compared with chocolate milk (6 g/ $191 \mathrm{~mL})$ and yogurt $(4 \mathrm{~g} / 173 \mathrm{~mL})$ did not reduce FI compared to all other beverages. One possible explanation may be their almost twofold higher carbohydrate content compared to milk. Independently, sucrose (Anderson et al. 1989; Birch et al. 1989) and milk proteins (Akhavan et al. 2010; Akhavan et al. 2014; Bellissimo et al. 2008; Panahi et al. 2014) suppress FI, suggesting that the combination of the two macronutrients as found in chocolate milk and yogurt trigger stronger satiety signals than either one alone.

Incomplete mealtime compensation occurred for all caloric beverages resulting in higher energy intakes at the meal compared with water. These data in children are consistent with previous studies in adults showing that mealtime caloric beverages by-pass caloric regulation (Panahi et al. 2013b), supporting recommendations that water may be the preferred mealtime beverage (Popkin et al. 2006). Although caloric beverages with meals add uncompensated 
calories to the meal, their contribution to excess energy intake can only be concluded through an examination of energy intakes for the remainder of the day.

Although no differences in beverage effects on FI were found between NW and OW/OB groups, as indicated by a lack of interaction between beverage and body weight group in either experiment, the $\mathrm{OW} / \mathrm{OB}$ children participating in the two experiments exhibited different characteristics. Comparing body weight groups, total FI was similar in Experiment 1, but OW/OB children ate 30\% more in Experiment 2. However, when corrected for body weight, NW children ate more than $\mathrm{OW} / \mathrm{OB}$ children in Experiment 1, while they ate similar amounts as OW/OB children in Experiment 2. The inconsistency in FI between groups in Experiments 1 and 2 is difficult to explain. In both OW/OB groups, body composition was similar with a ratio of fat mass:fat-free mass of 1:2, but those in Experiment 2 were $10 \mathrm{~kg}$ heavier and self-reported restrained eating behaviours. This is consistent with reported positive relationships between restrained eating and being OW/OB (Braet and Van Strien 1997; Snoek et al. 2007).

Disinhibition in eating patterns occur, leading to binging that in turn leads to weight gain (Snoek et al. 2007). Their report of restrained eating behaviour suggests they may have been exposed to more expressed concerns about their body weight (Braet and Van Strien 1997) but, as a result ate more freely when given access to palatable food in an environment that excluded their parents or peers.

Similar to previous studies in children, but in contrast to adults, pre-meal average appetite increased rather than decreased over time towards the test meal after one serving of the caloric beverages (Bellissimo et al. 2008; Patel et al. 2011), but the response of NW and OW/OB groups differed. Both pre- and post-meal subjective appetite were affected by treatment, with the greater increase reported after milk, but only in NW children (Figure 1B). Overall, mean appetite tended to increase more in the $\mathrm{OW} / \mathrm{OB}$ group but there was no treatment effect. Post-meal decrease in 
appetite also showed treatment effects but again only in NW children, with an overall mean decrease of $63 \pm 1.3 \mathrm{~mm}$ compared with $50 \pm 1.2 \mathrm{~mm}$ in the OW/OB children. As reported previously, there was no correlation between average appetite scores at $60 \mathrm{~min}$ with FI, suggesting that subjective appetite measures do not predict FI in children, in contrast to adults (Dove et al. 2009; Stubbs et al. 2000).

Although FI was similar after $2 \%$ milk and fruit punch in both experiments, pre-meal consumption of milk increased the concentrations of the satiety hormones GLP-1, reflecting the expected effect of consumption of milk proteins (Akhavan et al. 2014; Lejeune et al. 2006). Milk consumed with the meal increased post-meal PYY concentrations, also consistent with the reported increases in PYY responses to protein ingestion in healthy young men (Panahi et al. 2014) and with a previous study showing that PYY is one of the potential mediators of milk's inhibitory effects on hunger and FI (Akhavan et al. 2014). Although FI was not affected, an increase in these hormones is consistent with the reduced post-meal average appetite scores after milk (Figure 2), which may delay the return of hunger and the next meal-eating occasion (Batterham et al. 2002; Verdich et al. 2001), and supports the association between more frequent dairy consumption and weight control (Novotny et al. 2004; St-Onge et al. 2009).

Mealtime FI increased glycemic and appetite hormone responses more in OW/OB than in NW children. Post-meal insulin concentrations were higher in OW/OB children, but did not improve glucose responses, suggesting that OW/OB children may have reduced insulin sensitivity (Lomenick et al. 2009; Stock et al. 2005). However, the insulin response was concordant with higher post-meal GLP-1, which in turn may have mediated the post-meal reduction in ghrelin through its insulinotropic effects (Hagemann et al. 2007). In contrast, PYY concentrations did not differ between NW and OW/OB children, despite differences in baseline PYY values. 
This study adds to the limited literature examining the effects of dairy consumption on FI, glycemic, and appetite hormone responses in children, but has several limitations as designed. Although the study was designed to examine the effects of common serving sizes of beverages often consumed by children, interpretation of the appetite and metabolic responses is limited for several reasons. First, equal serving sizes of breakfast (300 kcal) and pre-meal and within meal beverages (130 kcal each) were provided for both NW and OW/OB groups. Because the latter were approximately 50\% heavier, impact of the beverages on them would be expected to be less, thus leading to a false negative effect in the OW/OB group. For example, the higher body weight of the OW/OB group may explain the absence of differences in their appetite responses to treatments in Experiment 1 and metabolic responses to milk and fruit punch in Experiment 2, in contrast to NW children. Second, Experiment 2 had a small sample size, and had unbalanced body weight and sex groups. Although differences were detected in glucose and appetite hormones, it was inadequate to properly assess FI and subjective appetite. As well, interpretation of gut hormone responses is limited by infrequent measures dictated by limited financial resources. Third, not all of the beverages were included in Experiment 2 also due to financial limitations. Thus a metabolic explanation for the reduction in FI after chocolate milk and yogurt, but not milk, remains to be determined.

In conclusion, dairy products consumed before and with a meal show more favourable effects on food intake, appetite and satiety hormones than consumption of a SSB, but all caloric beverages result in more calories consumed than if water is the beverage alone. 


\section{ACKNOWLEDGMENTS}

Authors thank Ting Ting Liu, Hannah Vien, Chesarahmia Dojo Soeandy, Minja Simeunovic, Nikita Ambekar, Sofiya Porodko, Parneeta Singh, Jessica Chu, Melanie Yeung, Munaza Jumil, Cheryl Arneson, and Ruslan Kubant for assistance with the project, as well as the parents and children enrolled in the studies for their participation. This study was supported by the Dairy Research Cluster, Dairy Farmers of Canada, Agriculture and Agri-Food Canada, and the Canadian Dairy Commission (Fund \#495981). The funders had no role in the study design, data collection and analysis, decision to publish, or preparation of the manuscript.

\section{CONFLICT OF INTEREST STATEMENT}

The authors declare that there are no conflicts of interest. 


\section{REFERENCES}

Akhavan, T., Luhovyy, B.L., Brown, P.H., Cho, C.E., and Anderson, G.H. 2010. Effect of premeal consumption of whey protein and its hydrolysate on food intake and postmeal glycemia and insulin responses in young adults. Am. J. Clin. Nutr. 91(4): 966-975.

doi:10.3945/ajen.2009.28406.

Akhavan, T., Luhovyy, B.L., Panahi, S., Kubant, R., Brown, P.H., and Anderson, G.H. 2014. Mechanism of action of pre-meal consumption of whey protein on glycemic control in young adults. J. Nutr. Biochem. 25(1): 36-43. doi:10.1016/j.jnutbio.2013.08.012.

Anderson, G.H., Catherine, N.L., Woodend, D.M., and Wolever, T.M. 2002. Inverse association between the effect of carbohydrates on blood glucose and subsequent short-term food intake in young men. Am. J. Clin. Nutr. 76(5): 1023-1030.

Anderson, G.H., Saravis, S., Schacher, R., Zlotkin, S., and Leiter, L.A. 1989. Aspartame: effect on lunch-time food intake, appetite and hedonic response in children. Appetite. 13(2): 93-103. Batterham, R.L., Cowley, M.A., Small, C.J., Herzog, H., Cohen, M.A., Dakin, C.L., et al. 2002. Gut hormone PYY(3-36) physiologically inhibits food intake. Nature. 418(6898): 650-654. doi:10.1038/nature02666.

Bellissimo, N., Desantadina, M.V., Pencharz, P.B., Berall, G.B., Thomas, S.G., and Anderson, G.H. 2008. A comparison of short-term appetite and energy intakes in normal weight and obese boys following glucose and whey-protein drinks. Int. J. Obes. (Lond). 32(2): 362-371. doi:10.1038/sj.ijo.0803709.

Birch, L.L., McPhee, L., and Sullivan, S. 1989. Children's food intake following drinks sweetened with sucrose or aspartame: time course effects. Physiol. Behav. 45(2): 387-395. 
Braet, C., and Van Strien, T. 1997. Assessment of emotional, externally induced and restrained eating behaviour in nine to twelve-year-old obese and non-obese children. Behav. Res. Ther. 35(9): 863-873.

Canadian-Dairy-Information-Centre. 2013. Consumption of Dairy Products [online]. Available from http://www.dairyinfo.gc.ca/index_e.php?s $1=$ dff-fcil\&s $2=$ cons\&s $3=$ conscdn $[$ accessed 03 November 2013].

de Onis, M., Onyango, A.W., Borghi, E., Siyam, A., Nishida, C., and Siekmann, J. 2007. Development of a WHO growth reference for school-aged children and adolescents. Bull. World Health Organ. 85(9): 660-667.

Dietz, W.H. 2006. Sugar-sweetened beverages, milk intake, and obesity in children and adolescents. J. Pediatr. 148(2): 152-154. doi:10.1016/j.jpeds.2005.12.045.

Dougkas, A., Reynolds, C.K., Givens, I.D., Elwood, P.C., and Minihane, A.M. 2011. Associations between dairy consumption and body weight: a review of the evidence and underlying mechanisms. Nutr. Res. Rev. 24(1): 72-95. doi:10.1017/S095442241000034X. Dove, E.R., Hodgson, J.M., Puddey, I.B., Beilin, L.J., Lee, Y.P., and Mori, T.A. 2009. Skim milk compared with a fruit drink acutely reduces appetite and energy intake in overweight men and women. Am. J. Clin. Nutr. 90(1): 70-75. doi:10.3945/ajen.2008.27411.

Garriguet, D. 2008. Beverage consumption of children and teens. Health Rep. 19(4): 17-22. Hagemann, D., Holst, J.J., Gethmann, A., Banasch, M., Schmidt, W.E., and Meier, J.J. 2007. Glucagon-like peptide 1 (GLP-1) suppresses ghrelin levels in humans via increased insulin secretion. Regul. Pept. 143(1-3): 64-68. doi:10.1016/j.regpep.2007.03.002.

Horlick, M., Arpadi, S.M., Bethel, J., Wang, J., Moye, J., Jr., Cuff, P., et al. 2002. Bioelectrical impedance analysis models for prediction of total body water and fat-free mass in healthy and HIV-infected children and adolescents. Am. J. Clin. Nutr. 76(5): 991-999. 
Huang, T.T., and McCrory, M.A. 2005. Dairy intake, obesity, and metabolic health in children and adolescents: knowledge and gaps. Nutr. Rev. 63(3): 71-80.

Janssen, I. 2013. The public health burden of obesity in Canada. Can. J. Diabetes. 37(2): 90-96. doi:10.1016/j.jcjd.2013.02.059.

Lejeune, M.P., Westerterp, K.R., Adam, T.C., Luscombe-Marsh, N.D., and WesterterpPlantenga, M.S. 2006. Ghrelin and glucagon-like peptide 1 concentrations, 24-h satiety, and energy and substrate metabolism during a high-protein diet and measured in a respiration chamber. Am. J. Clin. Nutr. 83(1): 89-94.

Lomenick, J.P., Melguizo, M.S., Mitchell, S.L., Summar, M.L., and Anderson, J.W. 2009. Effects of meals high in carbohydrate, protein, and fat on ghrelin and peptide YY secretion in prepubertal children. J. Clin. Endocrinol. Metab. 94(11): 4463-4471. doi:10.1210/jc.2009-0949. Loos, R.J., Rankinen, T., Leon, A.S., Skinner, J.S., Wilmore, J.H., Rao, D.C., et al. 2004. Calcium intake is associated with adiposity in Black and White men and White women of the HERITAGE Family Study. J. Nutr. 134(7): 1772-1778.

Marques-Vidal, P., Goncalves, A., and Dias, C.M. 2006. Milk intake is inversely related to obesity in men and in young women: data from the Portuguese Health Interview Survey 19981999. Int. J. Obes. (Lond). 30(1): 88-93. doi:10.1038/sj.ijo.0803045.

Novotny, R., Daida, Y.G., Acharya, S., Grove, J.S., and Vogt, T.M. 2004. Dairy intake is associated with lower body fat and soda intake with greater weight in adolescent girls. J. Nutr. 134(8): 1905-1909.

Panahi, S., El Khoury, D., Kubant, R., Akhavan, T., Luhovyy, B.L., Goff, H.D., et al. 2014. Mechanism of action of whole milk and its components on glycemic control in healthy young men. J. Nutr. Biochem. 25(11): 1124-1131. doi:10.1016/j.jnutbio.2014.07.002. 
Panahi, S., El Khoury, D., Luhovyy, B.L., Goff, H.D., and Anderson, G.H. 2013b. Caloric beverages consumed freely at meal-time add calories to an ad libitum meal. Appetite. 65: 75-82. doi:10.1016/j.appet.2013.01.023.

Panahi, S., Luhovyy, B.L., Liu, T.T., Akhavan, T., El Khoury, D., Goff, H.D., et al. $2013 a$. Energy and macronutrient content of familiar beverages interact with pre-meal intervals to determine later food intake, appetite and glycemic response in young adults. Appetite. 60(1): 154-161. doi:10.1016/j.appet.2012.09.018.

Patel, B.P., Anderson, G.H., Vien, S., Bellissimo, N., McCrindle, B.W., and Hamilton, J.K. 2014. Obesity, sex and pubertal status affect appetite hormone responses to a mixed glucose and whey protein drink in adolescents. Clin. Endocrinol. (Oxf). 81(1): 63-70. doi:10.1111/cen.12403.

Patel, B.P., Bellissimo, N., Thomas, S.G., Hamilton, J.K., and Anderson, G.H. 2011. Television viewing at mealtime reduces caloric compensation in peripubertal, but not postpubertal, girls. Pediatr. Res. 70(5): 513-517. doi:10.1038/pr.2011.738

10.1203/PDR.0b013e31822d783e.

Pereira, M.A., Jacobs, D.R., Jr., Van Horn, L., Slattery, M.L., Kartashov, A.I., and Ludwig, D.S. 2002. Dairy consumption, obesity, and the insulin resistance syndrome in young adults: the CARDIA Study. J. Am. Med. Assoc. . 287(16): 2081-2089.

Popkin, B.M., Armstrong, L.E., Bray, G.M., Caballero, B., Frei, B., and Willett, W.C. 2006. A new proposed guidance system for beverage consumption in the United States. Am. J. Clin. Nutr. 83(3): 529-542.

Shields, M., and Tremblay, M.S. 2010. Canadian childhood obesity estimates based on WHO, IOTF and CDC cut-points. Int. J. Pediatr. Obes. 5(3): 265-273. doi:10.3109/17477160903268282. 
Skinner, J.D., Bounds, W., Carruth, B.R., and Ziegler, P. 2003. Longitudinal calcium intake is negatively related to children's body fat indexes. J. Am. Diet. Assoc. 103(12): 1626-1631. doi:10.1016/j.jada.2003.09.018.

Snoek, H.M., van Strien, T., Janssens, J.M., and Engels, R.C. 2007. Emotional, external, restrained eating and overweight in Dutch adolescents. Scand. J. Psychol. 48(1): 23-32. doi:10.1111/j.1467-9450.2006.00568.x.

St-Onge, M.P., Goree, L.L., and Gower, B. 2009. High-milk supplementation with healthy diet counseling does not affect weight loss but ameliorates insulin action compared with low-milk supplementation in overweight children. J. Nutr. 139(5): 933-938. doi:10.3945/jn.108.102079. Stock, S., Leichner, P., Wong, A.C., Ghatei, M.A., Kieffer, T.J., Bloom, S.R., et al. 2005. Ghrelin, peptide YY, glucose-dependent insulinotropic polypeptide, and hunger responses to a mixed meal in anorexic, obese, and control female adolescents. J. Clin. Endocrinol. Metab. 90(4): 2161-2168. doi:10.1210/jc.2004-1251.

Stubbs, R.J., Hughes, D.A., Johnstone, A.M., Rowley, E., Reid, C., Elia, M., et al. 2000. The use of visual analogue scales to assess motivation to eat in human subjects: a review of their reliability and validity with an evaluation of new hand-held computerized systems for temporal tracking of appetite ratings. Br. J. Nutr. 84(4): 405-415.

van Strien, T., Frijters, J.E., Bergers, G.P., and Defares, P.B. 1986. The Dutch Eating Behavior Questionnaire (DEBQ) for assessment of restrained, emotional, and external eating behavior. Int. J. Eat. Disorder. 5(2): 295-315. doi:10.1002/1098-108X(198602)5:2<295::AIDEAT2260050209>3.0.CO;2-T.

Verdich, C., Flint, A., Gutzwiller, J.P., Naslund, E., Beglinger, C., Hellstrom, P.M., et al. 2001. A meta-analysis of the effect of glucagon-like peptide-1 (7-36) amide on ad libitum energy intake in humans. J. Clin. Endocrinol. Metab. 86(9): 4382-4389. doi:10.1210/jcem.86.9.7877. 
Table 1. Energy and macronutrient composition of beverages

\begin{tabular}{lccccc}
\hline & \multicolumn{4}{c}{ Beverages $^{a}$} \\
\cline { 2 - 6 } & Water $^{b}$ & Fruit & & $1 \%$ & $1.5 \%$ \\
& & Punch $^{c}$ & $2 \%$ Milk $^{c}$ & Chocolate & Yogurt \\
& & & Milk $^{b}$ & Drink $^{b}$ \\
\hline Weight (g) & 250 & 241 & 255.5 & 202.5 & 177.5 \\
Volume (mL) & 250 & 232 & 250 & 191 & 173 \\
Water Chaser (mL) & 0 & 18 & 0 & 59 & 77 \\
Total Volume (mL) & 250 & 250 & 250 & 250 & 250 \\
Energy (kcal) & 0 & 130 & 130 & 130 & 130 \\
Energy density (kcal/g) & 0 & 0.5 & 0.5 & 0.6 & 0.7 \\
Total Fat (g) & 0 & $<0.1$ & 5.2 & 1.9 & 2.4 \\
Protein (g) & 0 & 0.3 & 8.2 & 5.7 & 4.1 \\
Carbohydrate (g) & 0 & 32.1 & 12.7 & 22.8 & 23.2 \\
Total Sugars (g) & 0 & 25.8 & 11.2 & 18.8 & 17.9 \\
Fructose (g) & 0 & 14.2 & 0 & 0 & 0 \\
Glucose (g) & 0 & 9.8 & 0 & 0 & 0 \\
Sucrose (g) & 0 & 1.7 & 0 & 11.2 & 13.4 \\
Lactose (g) & 0 & 0 & 11.2 & 7.6 & 4.6 \\
Sodium (mg) & 0 & 0 & 109.2 & 154 & 59.7 \\
Calcium & 0 & 0 & 330 & 190 & 170 \\
\hline Da & & & & \\
\hline
\end{tabular}

${ }^{\bar{a}}$ Data provided by Maxxam Analytics, Mississauga, ON, Canada

${ }^{b}$ Beverages used in Experiment 1.

${ }^{c}$ Beverages used in Experiment 1 and 2. 
Table 2. Baseline characteristics of participants ${ }^{a}$

\begin{tabular}{|c|c|c|c|c|}
\hline \multirow[t]{2}{*}{ Characteristics } & \multicolumn{2}{|c|}{ Experiment 1} & \multicolumn{2}{|c|}{ Experiment 2} \\
\hline & $\begin{array}{l}\text { Normal Weight } \\
\qquad(n=16)\end{array}$ & $\begin{array}{c}\text { Overweight/Obese } \\
\quad(n=16)\end{array}$ & $\begin{array}{l}\text { Normal Weight } \\
\qquad(n=10)\end{array}$ & $\begin{array}{c}\text { Overweight/Obese } \\
\quad(n=10)\end{array}$ \\
\hline Age (y) & $12.0 \pm 0.3$ & $12.2 \pm 0.4$ & $12.4 \pm 0.7$ & $12.0 \pm 0.5$ \\
\hline Female:Male & $8: 8$ & $8: 8$ & $5: 5$ & $5: 5$ \\
\hline Body weight (kg) & $43.1 \pm 2.0$ & $59.3 \pm 3.0^{*}$ & $45.7 \pm 4.3$ & $69.7 \pm 6.3^{*}$ \\
\hline Height $(\mathrm{cm})$ & $155.5 \pm 2.1$ & $155.4 \pm 2.3$ & $155.7 \pm 5.5$ & $155.2 \pm 3.8$ \\
\hline BMI percentile & $46.7 \pm 7.0$ & $96.2 \pm 0.7^{*}$ & $50.8 \pm 9.5$ & $98.1 \pm 0.9^{*}$ \\
\hline Fat mass $^{b}(\mathrm{~kg})$ & $6.8 \pm 0.8$ & $20.7 \pm 2.0^{*}$ & $7.5 \pm 1.5$ & $24.9 \pm 4.5^{*}$ \\
\hline Fat-free mass ${ }^{b}(\mathrm{~kg})$ & $36.4 \pm 1.8$ & $38.6 \pm 1.6$ & $38.2 \pm 3.7$ & $44.9 \pm 3.6$ \\
\hline Restrained eating $^{c}$ & $1.5 \pm 0.1$ & $1.7 \pm 0.1$ & $1.4 \pm 0.1$ & $1.8 \pm 0.1^{*}$ \\
\hline \multicolumn{5}{|l|}{ Blood parameters ${ }^{d}$} \\
\hline Glucose $(\mathrm{mmol} / \mathrm{L})$ & & & $4.8 \pm 0.1$ & $4.9 \pm 0.1$ \\
\hline Insulin (pmol/L) & & & $88.4 \pm 9.2$ & $106.2 \pm 14.9$ \\
\hline Glucose:Insulin R & atio & & $0.07 \pm 0.1$ & $0.07 \pm 0.1$ \\
\hline GLP-1 (pmol/L) & & & $4.9 \pm 0.9$ & $5.5 \pm 1.3$ \\
\hline PYY (pg/mL) & & & $157.4 \pm 10.0$ & $86.2 \pm 8.9^{*}$ \\
\hline Total Ghrelin (pg/ & $\mathrm{mL})$ & & $517.5 \pm 36.2$ & $581.7 \pm 48.1$ \\
\hline \multicolumn{5}{|c|}{${ }^{a}$ Data are means \pm SEM. * Significantly different from normal weight $p<0.01$ within each } \\
\hline \multicolumn{5}{|c|}{${ }^{b}$ Body composition determined by Bioelectrical Impedance Analysis based on the Horlick } \\
\hline \multicolumn{5}{|c|}{ equation (Horlick et al. 2002). } \\
\hline \multicolumn{5}{|c|}{ 'Restrained eating was measured with the children's Dutch Eating Behaviour Questionnaire (van } \\
\hline Strien et al. 1986). & & & & \\
\hline
\end{tabular}


Table 3. Effect of beverages and body weight on pizza intake, energy intake at the meal, cumulative energy intake and caloric compensation $^{a}$

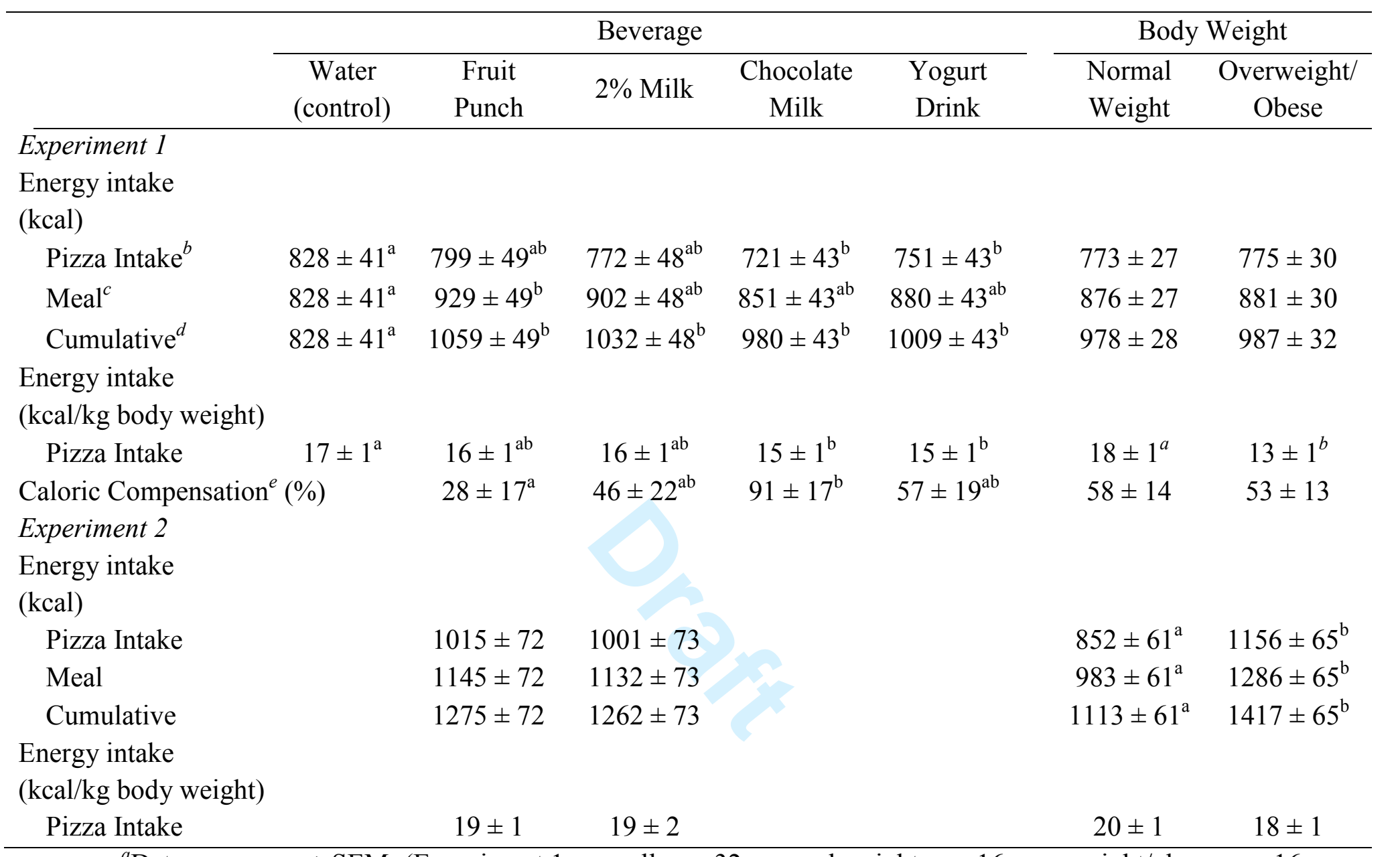

${ }^{a}$ Data are means \pm SEM; (Experiment 1: overall, $n=32$; normal weight, $n=16$; overweight/obese, $n=16$;

Experiment 2: overall, $n=20$; normal weight, $n=10$; overweight/obese, $n=10$ ). A two-factor ANOVA analysis for energy intake, energy intake adjusted for body weight and caloric compensation was used with beverage and body weight as main factors. Values in the same row with different superscript letters are significantly different, $p<0.05$.

${ }^{b}$ Pizza only consumed at $60 \mathrm{~min}$

${ }^{c}$ Beverage plus pizza consumed at $60 \mathrm{~min}$

${ }^{d}$ Pre-meal beverage consumed at baseline plus beverage and pizza consumed at $60 \mathrm{~min}$

${ }^{e}$ Caloric compensation $=[(\mathrm{kcal}$ consumed at meal after water control $-\mathrm{kcal}$ consumed at meal after preload)/kcal in the preload] x 100 . 
Table 4. Experiment 2: Mean changes from baseline pre- and post-meal blood glucose, insulin, and appetite hormone responses ${ }^{a}$

\begin{tabular}{|c|c|c|c|c|c|c|c|}
\hline \multirow[t]{2}{*}{ Biomarkers } & \multicolumn{2}{|c|}{$\begin{array}{l}\text { Normal Weight } \\
\quad(n=10)\end{array}$} & \multicolumn{2}{|c|}{$\begin{array}{l}\text { Overweight/Obese } \\
(n=10)\end{array}$} & \multicolumn{3}{|c|}{$P$} \\
\hline & 2\% Milk & Fruit Punch & 2\% Milk & Fruit Punch & Beverage & $\begin{array}{c}\text { Body } \\
\text { weight }\end{array}$ & Interaction \\
\hline \multicolumn{8}{|c|}{ Glucose (mmol/L) } \\
\hline Pre-meal ${ }^{b}$ & $0.2 \pm 0.2$ & $0.6 \pm 0.2$ & $0.2 \pm 0.2$ & $0.4 \pm 0.2$ & NS & NS & NS \\
\hline Post-meal $^{c}$ & $0.3 \pm 0.2^{\mathrm{a}}$ & $0.3 \pm 0.2^{\mathrm{a}}$ & $0.8 \pm 0.2^{\mathrm{b}}$ & $0.5 \pm 0.1^{\mathrm{b}}$ & NS & 0.02 & NS \\
\hline \multicolumn{8}{|c|}{ Insulin (pmol/L) } \\
\hline Pre-meal & $36.2 \pm 18.3$ & $73.0 \pm 28.0$ & $53.6 \pm 29.9$ & $58.3 \pm 37.7$ & NS & NS & NS \\
\hline Post-meal & $329.9 \pm 72.8$ & $264.4 \pm 54.5$ & $348.8 \pm 57.5$ & $378.0 \pm 48.0$ & NS & NS & NS \\
\hline \multicolumn{8}{|c|}{ GLP-1 (pmol/L) } \\
\hline Pre-meal & $0.2 \pm 0.2^{\mathrm{a}}$ & $-0.7 \pm 0.6^{\mathrm{b}}$ & $0.8 \pm 0.3^{\mathrm{a}}$ & $-0.7 \pm 0.6^{\mathrm{b}}$ & 0.01 & NS & NS \\
\hline Post-meal & $3.7 \pm 0.3$ & $2.7 \pm 0.8$ & $4.6 \pm 1.03$ & $5.3 \pm 0.9$ & NS & NS & NS \\
\hline \multicolumn{8}{|l|}{ PYY (pg/mL) } \\
\hline Pre-meal & $-13.4 \pm 9.4$ & $-7.7 \pm 7.0$ & $10.9 \pm 5.0$ & $-4.1 \pm 11.9$ & NS & NS & NS \\
\hline Post-meal & $62.9 \pm 10.5^{\mathrm{a}}$ & $26.5 \pm 12.3^{\mathrm{b}}$ & $48.3 \pm 9.8^{\mathrm{a}}$ & $33.7 \pm 9.8^{b}$ & 0.007 & NS & NS \\
\hline \multicolumn{8}{|c|}{ Ghrelin (pg/mL) } \\
\hline Pre-meal & $-48.6 \pm 13.1$ & $-69.0 \pm 31.2$ & $-11.5 \pm 25.1$ & $-20.2 \pm 19.0$ & NS & NS & NS \\
\hline Post-meal & $-55.2 \pm 21.6$ & $-71.4 \pm 18.4$ & $-153.8 \pm 37.8$ & $-107.0 \pm 48.2$ & NS & NS & NS \\
\hline \multicolumn{8}{|c|}{${ }^{a}$ Data are means \pm SEM; $(n=20)$. Two-factor ANOVA analysis for pre- and post-meal mean } \\
\hline \multicolumn{8}{|c|}{ factors. Values in the same row with different superscript letters are significantly different $(p<$} \\
\hline \multicolumn{8}{|l|}{$0.05)$} \\
\hline \multicolumn{8}{|c|}{${ }^{b}$ Pre-meal values are mean changes from baseline to 30 and $60 \mathrm{~min}$ before the test meal. } \\
\hline${ }^{c}$ Post-me & alues are $\mathrm{m}$ & ns changes a & r the test me & and calculat & 1 from 60 & o 115 a & 145 \\
\hline
\end{tabular}




\section{Figure captions}

Figure 1. Experiment 1: mean subjective appetite changes from baseline pre-meal (at 10, 20, 30 and $60 \mathrm{~min}$ ) and from 60 min post-meal (at 85, 95, 105, 115 and $145 \mathrm{~min}$ ) of (a) all, (b) normal weight and (c) overweight/obese children. Three-factor repeated-measures ANOVA followed by Tukey-Kramer post-hoc test was used to compare the effect of beverage. Bars with different superscript letters are significantly different, $(p<0.004)$, interaction between beverage and body weight, $(p<0.01)$ and time, $(p<0.001)$. Values are mean \pm SEM; $(n=32$ all children; $n=16$ normal weight; $n=16$ overweight/obese).

Figure 2. Experiment 2: mean subjective appetite changes from baseline pre-meal (at 10, 30 and $60 \mathrm{~min}$ ) and from $60 \mathrm{~min}$ post-meal (at, 85, 95, 105, 115 and $145 \mathrm{~min}$ ) of (a) all, (b) normal weight and (c) overweight/obese children. Three-factor repeated-measures ANOVA followed by Tukey-Kramer post-hoc test was used to compare the effect of beverage. *Significantly different from fruit punch, $(p<0.02)$, interaction between beverage and body weight, $(p<0.05)$ and time, $(p<0.001)$. Values are mean $\pm \operatorname{SEM} ;(n=20$ all children; $n=10$ normal weight; $n=10$ overweight/obese).

Figure 3. Experiment 2: Serum blood glucose changes from baseline for pre- (30 and $60 \mathrm{~min})$ and from $60 \mathrm{~min}$ for post-meal $(85,115$ and $145 \mathrm{~min})$. *Significantly different from normal weight. Two-factor ANOVA (Pre-meal: Beverage, $p>0.05$, Body weight, $p>0.05$, Beverage*Body weight, $p>0.05$; Post-meal: Beverage, $p>0.05$, Body weight, $p=0.02$, Beverage*Body weight, $p>0.05)$. Values are means \pm SEM; $(n=10$ normal weight; $n=10$ overweight/obese).

Figure 4. Experiment 2: Plasma (a) GLP-1, (b) PYY and (c) ghrelin changes from baseline. *Significantly different from fruit punch. Two-way ANOVA (beverages and time), TukeyKramer post hoc test, $p<0.05$. All values are means $\pm \mathrm{SEM} ; n=20$. 


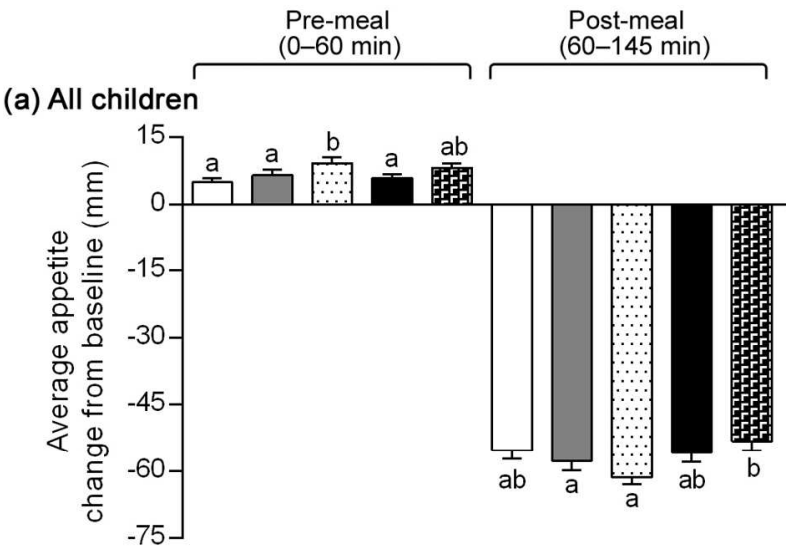

(b) Normal weight children

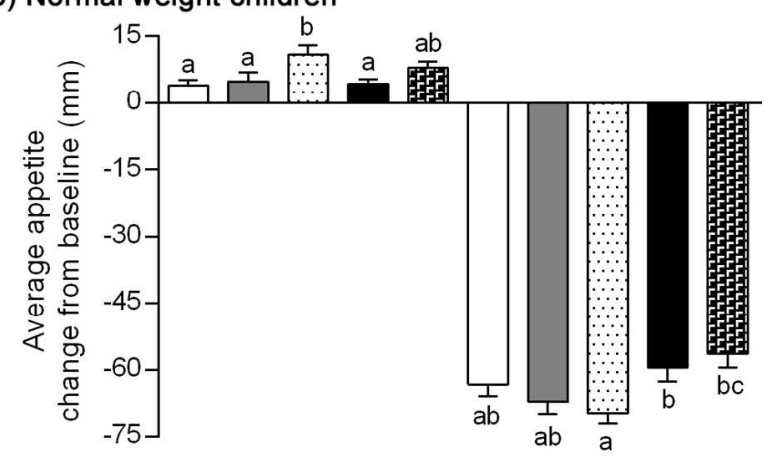

(c) Overweight/obese children

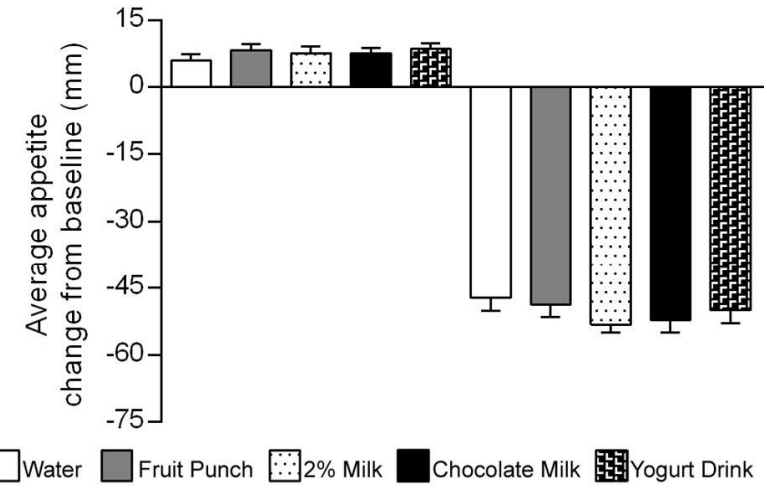

Figure 1.

$85 \times 171 \mathrm{~mm}(300 \times 300$ DPI $)$ 


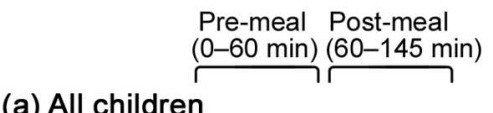

(a) All children

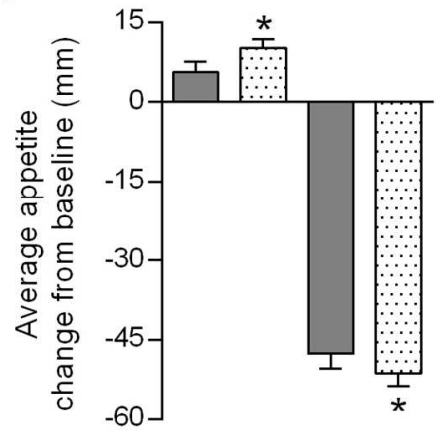

(b) Normal weight children

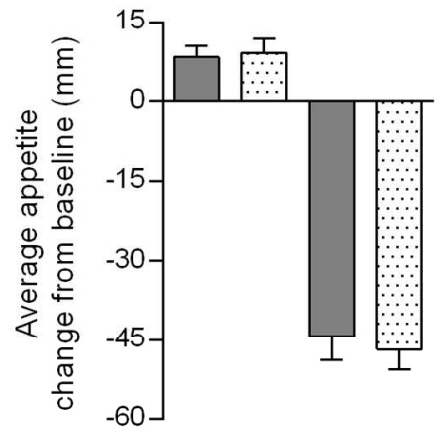

(c) Overweight/obese children

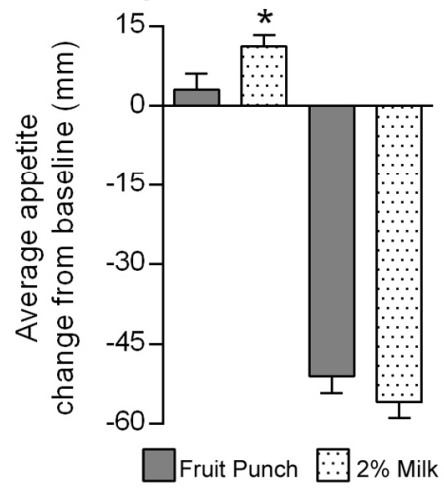

Figure 2.

$52 \times 165 \mathrm{~mm}(300 \times 300 \mathrm{DPI})$ 

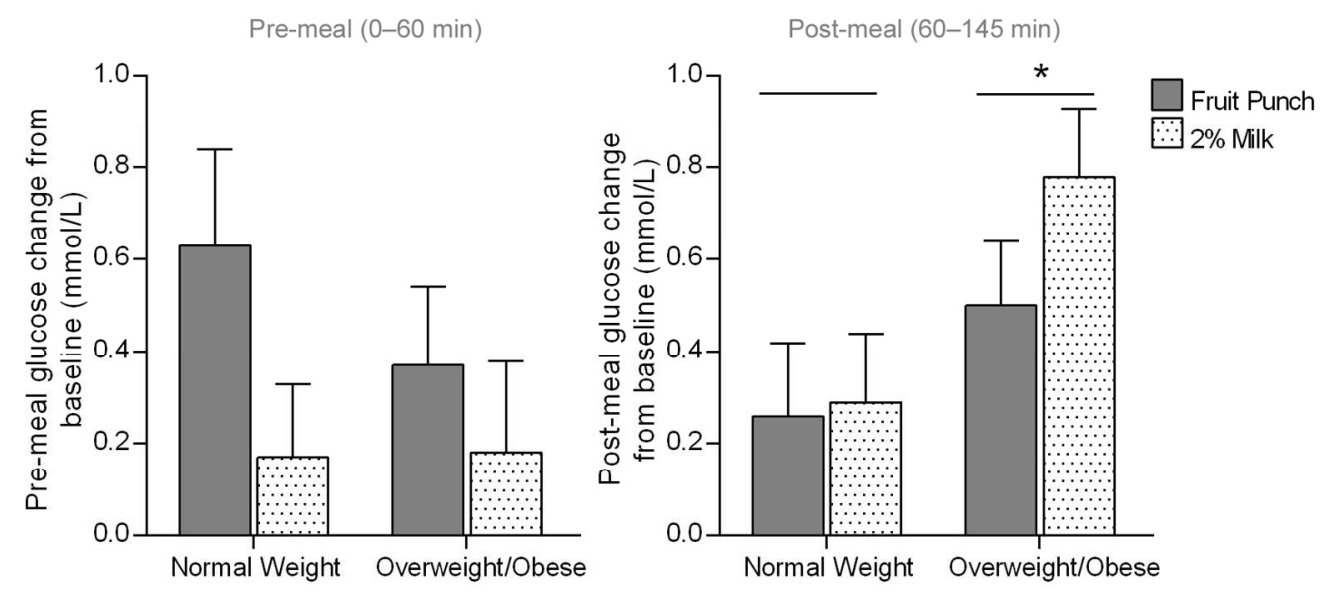

Figure 3.

$143 \times 63 \mathrm{~mm}(300 \times 300$ DPI $)$ 

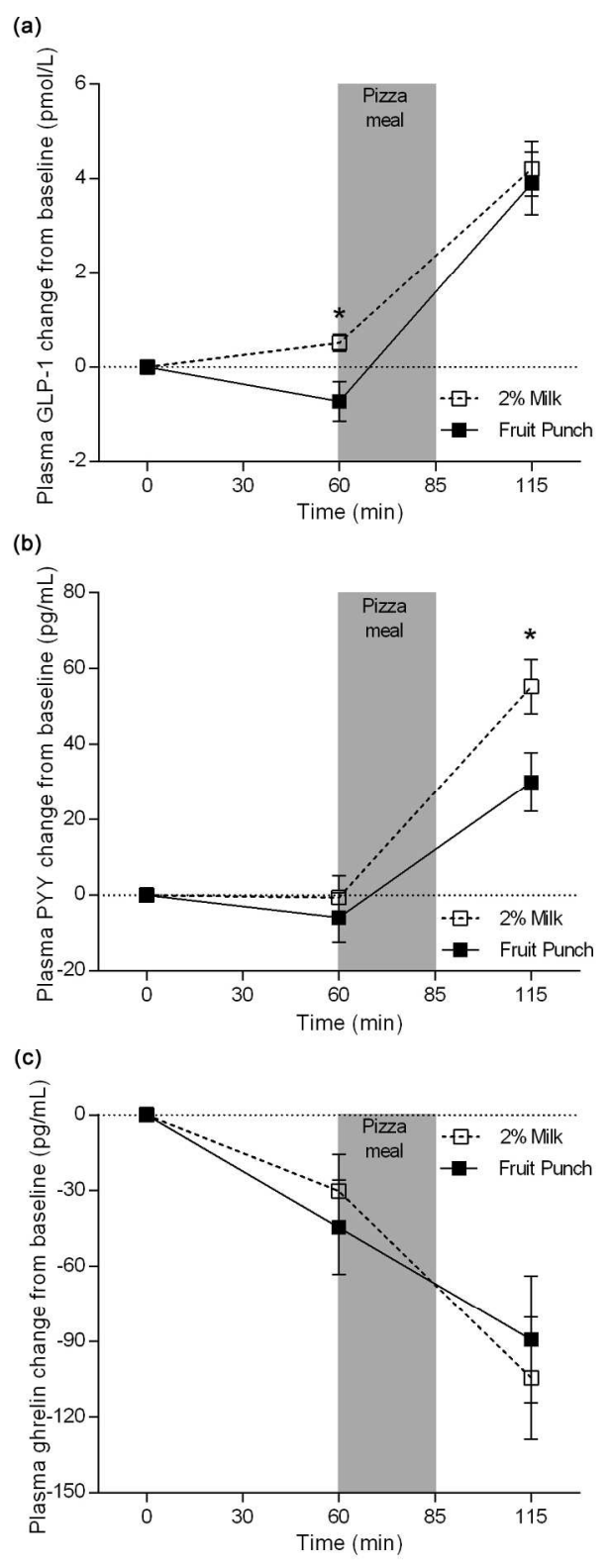

Figure 4.

$$
85 \times 225 \mathrm{~mm}(300 \times 300 \text { DPI })
$$

